\title{
Discussion on the paper: "When to intervene in the caries process? An expert Delphi consensus statement"
}

\author{
Jan Kühnisch ${ }^{1,2}$ \\ Received: 11 November 2019 / Accepted: 31 March 2020 / Published online: 17 April 2020 \\ (C) The Author(s) 2020
}

\section{Discussion}

There is an ongoing debate about caries management in children, adolescents, adults and elderly patients, which is mainly caused by divergent treatment recommendations in patients with the same diagnosis due to simple limitations, e.g. noncompliance for well-accepted dental measures, especially in cases of early childhood caries or of non-practicability of extensive or multi-visit procedures in vulnerable patient groups. This discussion is further complicated by the fact that several national dental health care systems do or do not reimburse all of the suggested preventive, non-/micro-invasive and/or operative caries management options or-in the worst case scenario-there is no public and/or individual dental care available for the overwhelming majority of a population. This means that caries will be treated with different dental procedures using different intervention levels in different regions or settings. Therefore, to reach a consensus about the important question "When should we intervene in the caries process?" basically requires a well-defined dental setup in which a dedicated group of patients may benefit from consensus recommendations. In the present paper, this aspect was not addressed appropriately, and it was unclear in which dental health care systems caries should be treated as proposed. Furthermore, it remains uncertain whether the consensus strategies are applicable to primary and/or permanent teeth as well as to low- or high-risk patients.

Jan Kühnisch

jkuehn@dent.med.uni-muenchen.de

1 Department of Conservative Dentistry and Periodontology, School of Dentistry, Ludwig-Maximilians-University of Munich, Munich, Germany

2 Poliklinik für Zahnerhaltung und Parodontologie, Ludwig-Maximilians-Universität München, Goethestraße 70, 80336 München, Germany
The consensus paper refers to several factors that may determine thresholds for dental intervention, e.g. caries activity, cavitation, cleanability, caries risk, age and dentition. With respect to the available literature, it must be clearly stated that caries activity and cleanability are weak variables that were not (fully) validated and should therefore have a limited impact on treatment decisions. When considering, first, "caries activity", it has to be noted that this variable has to be understood as a composite diagnostic index that contains several sub-factors. Each of these sub-variables may indicate an increased probability of whether or not caries may progress. While there seems to be a sound justification in relation to caries aetiology on the one hand, there currently are - on the other hand - no scientific and statistically proven algorithms available to quantify and validate caries activity. For this reason, the determination of caries activity is not fully verifiable, and there are substantial doubts from a strictly scientific point of view that caries activity could serve as a primary variable in the decision-making process. The same is even more valid for "cleanability" due to the following reasons. First, it should be noted that in the case of the presence of a cavitation, the patient has proved their inability to clean a formerly intact tooth surface. Therefore, the probability seems to be high that the attempt to constantly clean cavitated caries lesions will similarly fail when choosing a non-invasive intervention strategy. Second, from a scientific point of view, there have been no clinical data published on this issue. Consequently, I have great doubts that this unproven factor should become a part of the decision-making process today. Contrary to these "hardto-measure" factors, it is especially surprising that the importance of the caries extent was mostly neglected. When weighting the clinical importance and practicability of the available variables, it must be concluded that "cavitation" and "caries extent" seem to be of the highest relevance in the decision-making process and provide a large amount of categorical and/or quantifiable information. The third variable that may be useful is the caries activity/risk assessment, which mainly 
influences the decision between no intervention or non-/ micro-invasive preventive dental care (Fig. 1).

Another important clinical question - which unfortunately was not fully considered in the consensus paper - is "Which dentin caries depth should be used as the threshold to distinguish between non-operative and operative dental care, especially in non-cavitated caries lesions?". Here, a dentin caries extent of $33 \%$ was repeatedly suggested as a possible threshold [3], which was based on the fact that diagnostically incorrect decisions can most likely be ruled out [2]. With respect to the commonly known fact that the radiographic caries extent is typically less pronounced in comparison with the clinical/histological caries extension, I suggest also considering less extensive thresholds of dentin caries involvement (Fig. 1). Another argument for using a more restrictive cut-off is the permeable tubular dentin structure, which may lead to pulpal inflammation when caries have reached the dentin. Regardless of what the contemporary intervention threshold level should be, dental professionals may accept minimal dentin involvement of the caries process before operative intervention is indicated. Therefore, I would like to suggest discussing better threshold intervals instead of strict cut-off values to recognize the spectrum of opinions that exists.

The clinical meaning and indication for "mixed interventions" (non-restorative caries control and Hall technique) is a controversial subject that is currently being discussed. While both techniques have been described mainly for primary teeth, the expert group obviously generalized its clinical use for both dentitions. This raises the important question "What are the specific circumstances or concrete clinical situations in which mixed interventions are truly indicated in permanent teeth?"
Unfortunately, few specific indications are given by the expert group on the basis of the existing clinical data. From a personal perspective in a setting that can offer the full spectrum of individualised dental care to patients, "mixed interventions"and especially the non-restorative cavity control approachshould be considered an exceptional treatment option in both dentitions because the basic treatment goals cannot be foreseeably fulfilled, most importantly, preserving and maintaining pulp vitality. In this context, I would like to suggest that dentinal cavities or lesions with relevant dentin caries involvement should be restored, aiming to protect tubular dentin and its underlying pulpal tissue (Fig. 1); otherwise, functionality is at risk. Furthermore, dental restorations seal the cavity, reinstate the tooth anatomy, avoid mesial drifts, prevent tilt effects of neighbourhood teeth and block elongation of antagonists, prevent food impaction, positively contribute to the oral healthrelated quality of life and are a long-term treatment option, especially in situations in which it is possible to reduce or eliminate the formerly diagnosed caries risk and activity.

Another important issue that is missing in the discussion paper is a "backstop" mechanism in the case of deep caries lesions, which was most recently defined by the European Society of Endodontology as caries reaching the inner quarter of dentine [1], which threatens the functionality of the pulpodentinal complex. The consideration of mixed interventions, including non-restorative cavity control, in those cases [4, Figs. 3 and 4$]$ is hard to justify clinically. Therefore, I recommend describing the full spectrum of patient- and tooth-related (contra-)indications for each of the available treatment options in detail.

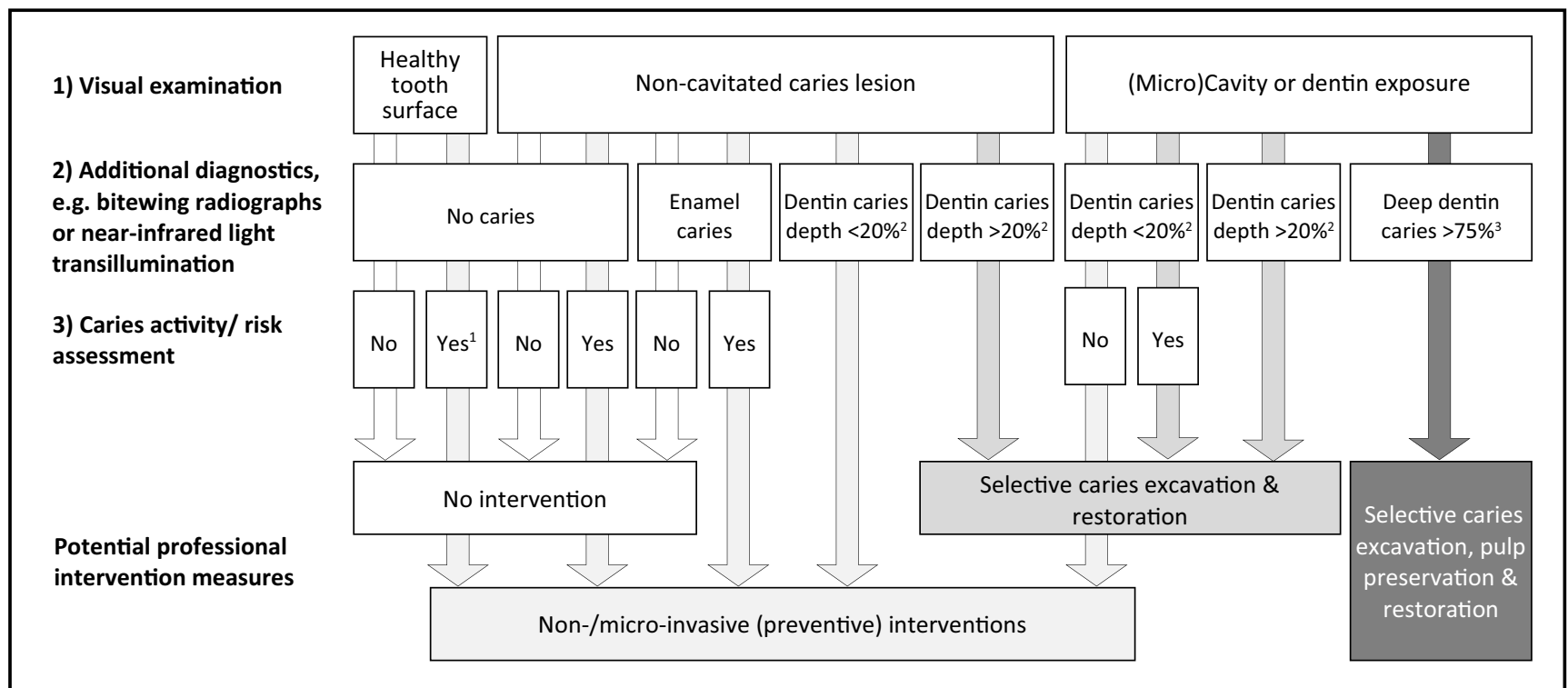

Fig. 1 Summary of potential treatment strategies in primary and permanent teeth for caries lesions in dental healthcare systems that provide full access to preventive and operative dental measures. It is noteworthy that in the case of early childhood caries, patients with extreme caries experience, less cooperative individuals or institutionalized/medically compromised subjects, divergent and individual decisions have to be made. ${ }^{1}$ Occlusal surfaces with a caries are susceptible to fissure patterns. ${ }^{2}$ The suggested dentin caries depth has to be understood as a subjective threshold that has not been scientifically fully proved. ${ }^{3}$ This definition was taken from [1] 
Additionally, no knowledge gaps were described in the consensus recommendation paper, which has to be considered another drawback of the discussion paper. This seems to be of high importance because readers want to differentiate between well-proven, data-based recommendations and lower-grade expert opinions.

Funding information Open Access funding provided by Projekt DEAL.

\section{Compliance with ethical standards}

Conflict of interest The author declares that he has no conflict of interest.

Ethical approval This letter does not contain any original data from unpublished studies with human participants or animals which potentially require approval.

Open Access This article is licensed under a Creative Commons Attribution 4.0 International License, which permits use, sharing, adaptation, distribution and reproduction in any medium or format, as long as you give appropriate credit to the original author(s) and the source, provide a link to the Creative Commons licence, and indicate if changes were made. The images or other third party material in this article are included in the article's Creative Commons licence, unless indicated otherwise in a credit line to the material. If material is not included in the article's Creative Commons licence and your intended use is not permitted by statutory regulation or exceeds the permitted use, you will need to obtain permission directly from the copyright holder. To view a copy of this licence, visit http://creativecommons.org/licenses/by/4.0/.

\section{References}

1. Duncan HF, Galler KM, Tomson PL, Simon S, El-Karim I, Kundzina R, Krastl G, Dammaschke T, Fransson H, Markvart M, Zehnder M, Bjørndal L (2019) European Society of Endodontology position statement: management of deep caries and the exposed pulp. Int Endod J 52:923-934. https://doi.org/10.1111/iej.13080

2. Ekstrand KR, Ricketts DN, Kidd EA (1997) Reproducibility and accuracy of three methods for assessment of demineralization depth of the occlusal surface: an in vitro examination. Caries Res 31:224 231

3. Schwendicke F, Frencken JE, Bjørndal L, Maltz M, Manton DJ, Ricketts D, Van Landuyt K, Banerjee A, Campus G, Doméjean S, Fontana M, Leal S, Lo E, Machiulskiene V, Schulte A, Splieth C, Zandona AF, Innes NP (2016) Managing carious lesions: consensus recommendations on carious tissue removal. Adv Dent Res 28:5867. https://doi.org/10.1177/0022034516639271

4. Schwendicke F, Splieth C, Breschi L, Banerjee A, Fontana M, Paris S, Burrow MF, Crombie F, Page LF, Gatón-Hernández P, Giacaman R, Gugnani N, Hickel R, Jordan RA, Leal S, Lo E, Tassery H, Thomson WM, Manton DJ (2019) When to intervene in the caries process? An expert Delphi consensus statement. Clin Oral Investig 23:3691-3703. https://doi.org/10.1007/s00784-019-03058-w

Publisher's note Springer Nature remains neutral with regard to jurisdictional claims in published maps and institutional affiliations. 